\title{
Induction of major heat-shock proteins of Saccharomyces cerevisiae, including plasma membrane Hsp30, by ethanol levels above a critical threshold
}

\author{
P. W. Piper, ${ }^{1}$ K. Talreja, ${ }^{1}$ B. Panaretou, ${ }^{1}$ P. Moradas-Ferreira, ${ }^{2}$ K. Byrne, ${ }^{3}$ \\ U. M. Praekelt, ${ }^{3}$ P. Meacock, ${ }^{3}$ M. Récnacq ${ }^{4}$ and H. Boucherie ${ }^{4}$
}

Author for correspondence: P. W. Piper. Tel: +44 713877050 ext. 2212. Fax: +44 713807193.

\footnotetext{
1 Department of Biochemistry and Molecular Biology, University College London, London WC1E 6BT, UK

2 Instituto de Ciencias Biomedicas de Abel Salazar, Universidade do Porto, 4000 Porto, Portugal

3 Department of Genetics, University of Leicester, Leicester LE1 7RH, UK

4 Institut de Biochemie et Genetique Cellulaires, Université de Bourdeaux II, France
}

\begin{abstract}
Many of the changes induced in yeast by sublethal yet stressful amounts of ethanol are the same as those resulting from sublethal heat stress. They include an inhibition of fermentation, increased induction of petites and stimulation of plasma membrane ATPase activity. Ethanol, at concentrations $(4-10 \%, v / v)$ that affect growth and fermentation rates, is also a potent inducer of heat-shock proteins including those members of the Hsp70 protein family induced by heat shock. This induction occurs above a threshold level of about $4 \%$ ethanol, although different heat-shock proteins and heat-shock gene promoters are optimally induced at different higher ethanol levels. In addition ethanol (6-8\%) causes the same two major changes to integral plasmamembrane protein composition that result from a sublethal heat stress, reduction in levels of the plasma membrane ATPase protein and acquisition of the plasma membrane heat-shock protein Hsp30.
\end{abstract}

Keywords: Saccbaromyces cerevisiae, stress response, ethanol, heat-shock proteins, plasmamembrane proteins

\section{INTRODUCTION}

The increasing ethanol level during batch fermentation of Saccharomyces cerevisiae on high sugar substrates acts to cause reductions in the specific growth rate, the fermentation rate and cell viability (see van Uden, 1984a, for literature). These effects become much more severe with increasing temperature, the optimum and maximum temperatures of growth becoming appreciably depressed in the presence of ethanol levels above about $3 \%(\mathrm{v} / \mathrm{v})$, while thermal death on exposure to extreme temperatures is enhanced (van Uden, 1984a, b). These adverse influences of ethanol on the growth, viability and fermentation of $S$. cerevisiae have been largely explained in terms of its effects on membrane-associated processes (Leao \& van Uden, 1984, 1985; Jones, 1989; Rose, 1993). Not only are these toxic effects influenced by the lipid composition of yeast cell membranes but growth in the presence of ethanol causes changes to membrane lipids which are possibly part of an adaptive response (reviewed in Rose, 1993, and Lloyd et al., 1993). The concentration

Abbreviations: Hsps, heat-shock proteins; 1D, one-dimensional. of ethanol that totally inhibits $S$. cerevisiae growth is also remarkably medium- and strain-dependent (Rose, 1993).

Several of the changes induced in yeast by exposure to stressful ethanol levels are identical to those caused by a heat stress. It is not surprising therefore that ethanol acts in a synergistic way to increase the damage caused by heat (van Uden, 1984a, b; Aguilera \& Benitez, 1989). Both heat and ethanol cause membrane disordering and protein denaturation (Casey \& Ingledew, 1986; Piper, 1993), besides an inhibition of glycolysis and an enhanced induction of petites (Neves \& Francois, 1992; Leao \& van Uden, 1982; van Uden, 1984a, b). Ethanol also inhibits glucose transport (Leao \& van Uden, 1982, 1985). Both stresses increase the permeability of the plasma membrane, resulting in an increased passive proton influx that acts to dissipate the electrochemical potential gradient that the cell maintains at this membrane. This is reflected in the decline in intracellular $\mathrm{pH}$ that is observed both with ethanol addition (Leao \& van Uden, 1984) and with heat shock (Coote et al., 1991 ; Coote, 1993). Ethanol and heat stress will adversely affect those vital functions for which a plasma membrane electrochemical gradient is essential, processes such as nutrient uptake, the main- 
Table 1. Yeast strains used in this study

\begin{tabular}{|c|c|}
\hline Strain & Relevant genotype \\
\hline MW109* & a leu 2 trp 1 ura 3 bis 3 lys 2 \\
\hline MW115* & $\alpha$ leu 2 trp 1 ura 3 bis 3 lys 2 ssa $3::$ TRP1 ssa $4:: U R A 3$ \\
\hline MW116* & $\alpha$ leu2 trp1 ura3 bis 3 lys 2 ssa $1:$ :HIS3 ssa2:: LEU2 ssa $3::$ TRP1 \\
\hline MW121* & $\alpha$ leu 2 trp 1 ura 3 bis 3 lys 2 ssa $1::$ HIS 3 ssa $3::$ TRP 1 ssa $4:: U R A 3$ \\
\hline MW122* & $\alpha$ leu 2 trp1 ura 3 bis 3 lys 2 ssa $4:: U R A 3$ \\
\hline MW123* & $\alpha$ leu 2 trp 1 ura 3 bis 3 lys 2 ssa $1::$ HIS 3 ssa $2::$ LEU 2 \\
\hline MW127* & $\alpha$ leu2 $\operatorname{trp} 1$ ura 3 bis 3 lys 2 ssa $3:: T R P 1$ \\
\hline BJ2168† & a leu2-3,112 trp1 ura3-52 prb1-1122 pep4-3 prc407 gal2 \\
\hline PMY501‡ & $\alpha$ leu2-3,112 bis4 ura3::pDP501 \\
\hline PMY3(pUP41a) $\S$ & $\alpha u r a^{3}$ pUP41a \\
\hline
\end{tabular}

* These strains are described in Werner-Washburne et al. (1987).

† Used for an earlier study on the effects of heat shock on plasma membrane protein composition (Panaretou \& Piper, 1992).

$\ddagger$ A derivative of strain PMY1.1 transformed to uracil prototrophy with the integrative UR A3-containing vector pDP501, a plasmid bearing a lacZ gene under the control of the UBI4 promoter sequences $(-767$ to -7 relative to the UBI4 ATG) (Kirk, 1993).

$\$ A$ uracil prototroph transformant of PMY3 carrying the centromeric vector pUP41a which carries $U R A 3$ plus the HSP12 promoter ( -609 to +14 relative to the ATG) fused in-frame to the lac $Z$ coding region (U. M. Praekelt \& P. Meacock, unpublished).

tenance of potassium balance, and the regulation of intracellular $\mathrm{pH}$ (Serrano, 1991).

Heat shock and ethanol induce protective responses in yeast that show a high degree of similarity. Both sublethal heat shock (Coote et al., 1991) and addition of ethanol (Cartwright et al., 1987; Rosa \& Sa-Correia, 1991) dramatically stimulate the activity of plasma-membrane ATPase, the enzyme largely responsible for maintaining the proton gradient across the plasma membrane (Serrano, 1991). These increases in ATPase activity cause an enhanced catalysed proton efflux that counteracts the dissipation of proton motive force resulting from the stress-induced increase in membrane permeability. It is not surprising, therefore, that mutations that alter plasmamembrane ATPase activity also influence cellular tolerances of both ethanol and heat (Panaretou \& Piper, 1990; Coote, 1993). Heat and ethanol also induce heatshock proteins (Hsps) in both yeast (Plesset et al., 1982) and other organisms (Nover, 1991). These evolutionarily conserved proteins were originally characterized on the basis of their strong induction by heat shock, but they are also induced by a number of chemical agents including ethanol. The trigger for their induction is probably the cytoplasmic accumulation of aberrant or partially denatured protein (Ananthan $e t$ al., 1985). Thus ethanol may be an inducer of Hsps through its destabilization of the hydrophobic interactions of protein structure which leads to the association of Hsp chaperones with these destabilized proteins and the concomitant activation of heatshock genes (Mager \& Moradas-Ferreira, 1993).

While it is clear that major Hsps are ethanol-inducible in yeast (Plesset $e$ t al., 1982), it is not obvious from published data if this induction is comparable with the induction of these same proteins by heat shock, or if perhaps only a subset of yeast Hsps are strongly ethanol-inducible. This report collates experiments from a number of laboratories that clarify the ethanol induction of the major S. cerevisiae Hsps and the range of ethanol concentrations most effective in this induction. It also reports the first study of the major effects of ethanol on plasma-membrane protein composition.

\section{METHODS}

Yeast strains, culture and conditions of ethanol and heat stress. The strains used for this study are listed in Table 1. Cultures were grown with vigorous shaking at $25^{\circ} \mathrm{C}$ in standard defined (SD) pH 6.8 medium, with $2 \%(\mathrm{w} / \mathrm{v})$ glucose as initial carbon source, plus necessary amino acid supplements (Sherman et al., 1983). They were used for ethanol stress experiments when in mid-exponential phase $\left(5 \times 10^{6}\right.$ cells $\left.\mathrm{ml}^{-1}\right)$, by which stage the medium ethanol levels produced by fermentation were less than $0.3 \%$. To heat shock cells, cultures were shifted to $39^{\circ} \mathrm{C}$ for $40 \mathrm{~min}$ prior to harvesting, this being the optimum temperature for induction of heat-shock element sequences (Kirk \& Piper, 1991a, and references cited therein). To ethanol stress cultures the stated amount of additional ethanol was added to cultures and incubation continued at $25^{\circ} \mathrm{C}$.

Pulse-labelling of proteins. Pulse-labelling of proteins with $\left[{ }^{3} \mathrm{H}\right]$ leucine was as described by Cheng \& Piper (1994). For efficient uptake of labelled amino acids in the presence of $4-10 \%$ ethanol it is essential that the $\mathrm{pH}$ of the medium is greater than 6.0 as ethanol strongly inhibits uptake of labelled amino acids in cultures of lower $\mathrm{pH}$ (unpublished observations).

Protein analysis. Samples of total cell protein were isolated as described by Piper et al. (1988). Protein determinations were performed using the Bio-Rad Protein Assay Kit and bovine serum albumin as standard. Protein samples were prepared for gel electrophoresis by incubation at $37{ }^{\circ} \mathrm{C}$ in SDS-protein gel sample buffer, then analysed on one-dimensional $12.5 \%$ or $7 \%$ 

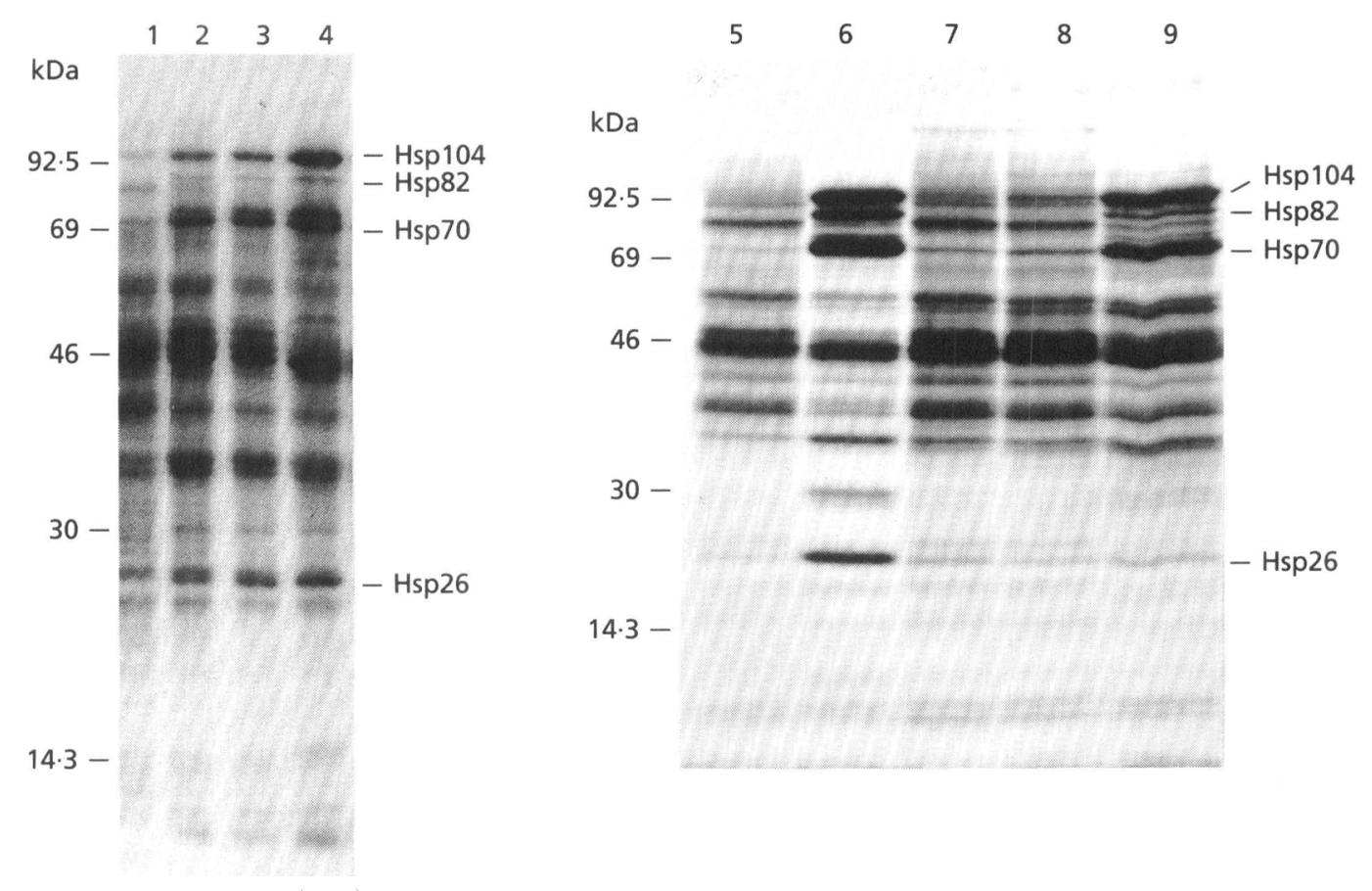

Fig. 1. Autoradiographs of two $12 \cdot 5 \%$ SDS-gels showing the proteins labelled in S. cerevisiae BJ2168 cells during heat and ethanol stress. Cells were pulse-labelled for $40 \mathrm{~min}$ at $25^{\circ} \mathrm{C}$, in the absence of ethanol (lanes 1,5$)$; at $25^{\circ} \mathrm{C}$ with $2 \%$ (lane 7), $4 \%$ (lane 8), $6 \%$ (lane 2), $8 \%$ (lanes 3, 9) or $10 \%$ ethanol (lane 4); or immediately after heat shock to $40{ }^{\circ} \mathrm{C}$ (lane 6). Molecular mass marker positions are indicated on the left, and major Hsps on the right of each autoradiograph.

(w/v) SDS-polyacrylamide gels. Gel staining with Coomassie brilliant blue, detection of labelled proteins by fluorography and blotting of proteins onto nitrocellulose membrane was according to standard procedures (Piper et al., 1988; Panaretou \& Piper, 1992).

Plasma membrane purification and protein analysis. Purification of plasma membranes, assessment of the purity of membrane preparations and analysis of plasma-membrane proteins on $12.5 \%$ gels was as described by Panaretou \& Piper (1992). Blotted plasma-membrane proteins were analysed for Hsp30 as described by Récnacq \& Boucherie (1993).

Northern blotting of RNA. Total cell RNA was prepared, Northern blotted onto Hybond $\mathrm{N}$ membranes, and probed to HSP26, HSP12 and ACT1 gene probes as described by Piper et al. (1988).

lacZ expression measurements. $\beta$-Galactosidase activity, measured as in Kirk \& Piper (1991a,b), is presented as foldinduction relative to the low constant level of $\beta$-galactosidase in uninduced cultures at $25^{\circ} \mathrm{C}$.

\section{RESULTS}

\section{A threshold concentration of approximately $4 \%$ ethanol is required for appreciable Hsp induction, subsets of these proteins showing optimal induction at different higher ethanol levels}

The addition of $4-10 \%$ ethanol to exponentially growing yeast cultures causes strong induction of a few specific proteins. From 1D gel analyses Plesset $e t$ al. (1982) found that many of these were the same as proteins induced by heat shock (see also Fig. 1). However there has been no systematic study showing if each major yeast Hsp is inducible to the same extent by ethanol as by heat shock, or indeed whether all Hsps are optimally induced at the same ethanol concentration. Most heat-shock genes of $S$. cerevisiae have now been characterized (Mager \& MoradasFerreira, 1993; Parsell \& Lindquist, 1993) and the availability of several strains with targeted inactivation of these genes facilitates comparison of the ethanol and heat inducibility of most individual Hsps.

We have observed that there is a threshold concentration for appreciable Hsp induction by adding ethanol to vegetative yeast cultures. Appreciable induction started to become detectable by protein pulse-labelling with the addition of approximately $4 \%$ ethanol (Fig. 1, lane 8), negligible induction being observed at lower ethanol levels. We also found that different Hsps were optimally induced at different levels of ethanol above $4 \%$; also, while some Hsps appear to be induced as strongly by ethanol as by heat shock, others were not. The induction of Hsp104, Hsp70 and Hsp26 progressively increased as the ethanol addition increased from 4 to $10 \%$ (Fig. 1, lanes 1-4). At $8 \%$ ethanol (Fig. 1, lanes 3 and 9), Hsp104 and $\mathrm{Hsp} 70$ are induced almost as strongly as with heat shock, but this is not the case for Hsp82 and Hsp26 (Fig. 1 , lanes 6 and 9).

One of the proteins induced most strongly by ethanol is Hsp104, an important determinant of ethanol tolerance (Sanchez et al., 1992) and a homologue of the $\operatorname{clp} A$ and 
$c l p B$ proteases of E. coli (Parsell et al., 1991). The form of the Hsp90 protein which is most strongly heat-inducible (Hsp82) was observed to be induced by ethanol to a lesser degree than by heat shock (Fig. 1). S. cerevisiae has two functionally equivalent Hsp90 genes (HSC 82 and HSP 82; Borkovich et al., 1989). HSC82 displays a high constitutive expression that increases only slightly after heat shock, whereas HSP82 displays much lower basal expression yet is strongly activated by heat shock. HSC 82 therefore contributes most of the Hsp 90 present during, normal vegetative growth, whereas HSP82 expression is mainly responsible for the increase in $\mathrm{Hsp} 90$ protein with heat shock (Borkovich et al., 1989). The product of HSP82 $\left(M_{\mathrm{r}} 81419\right)$, distinguishable from that of HSC82 $\left(M_{\mathrm{r}} 80885\right)$ by its slightly slower mobility on $1 \mathrm{D}$ gels of stress-induced proteins, is the Hsp90 form induced by ethanol (Fig. 1, lanes 6 and 9; also data not shown).

\section{Induction of small heat shock proteins by ethanol}

A recent study has confirmed that several small Hsps are induced by ethanol (Gropper \& Rensing, 1993) although loss of at least one of these proteins (Hsp26) does not affect ethanol tolerance (Petko \& Lindquist, 1986; Susek \& Lindquist, 1989). Northern analysis of the mRNA of strain BJ2168 probed for HSP26 gene transcripts indicated that Hsp26 mRNA, undetectable with addition of $2 \%$ ethanol, is barely detectable after addition of $4 \%$ ethanol (Fig. 2b). However it is much more strongly induced with further increases in ethanol concentration, eventually (at $10 \%$ ethanol) becoming as strongly induced by ethanol as by heat shock (Fig. 2b). Protein pulselabelling in this strain also shows the increasing Hsp26 induction with increase in ethanol (Fig. 1, lanes 1-4).

We also analysed the ethanol inducibility of the heatinducible HSP12 (Praekelt \& Meacock, 1990) and UBI4 (Finley et al., 1987) promoters using strains containing the appropriate promoter-lac $Z$ fusions (Tables 1,2). An HSP12 promoter-lac $Z$ fusion carried on an episomal centromeric vector [PMY3(pUP41a); Table 1] was optimally induced by 4-6\% ethanol. Its induction rapidly decreased to uninduced levels at higher ethanol concentrations (Table 2). This maximal 12 -fold induction of the HSP12 promoter-lac $Z$ fusion by ethanol compares to an optimal 61 -fold induction of the same sequence by heat shock (Table 2) and 20 -fold induction by methanol (U. M. Praekelt and P. Meacock, unpublished results). Northern blotting (Fig. 2c) provided data broadly in agreement with these lac $Z$ expression measurements, the Hsp12 mRNA of PMY3(pUP41a) displaying optimal induction at $6 \%$ ethanol and declining at higher ethanol levels. The $10 \%$ ethanol addition that caused a strong Hsp26 mRNA induction in BJ2168 resulted in no Hsp12 mRNA induction in PMY3(pUP41a) (Fig. 2).

The integrated UBI4 promoter-lac $Z$ fusion of strain PMY501 (Table 1) showed optimal 5.2-fold induction at 4-6\% ethanol (Table 2). This induction was more sustained at higher ethanol levels as compared to that of the HSP12 promoter-lacZ fusion (Table 2) and was similar to the maximal four- to fivefold inducibility of the (a)
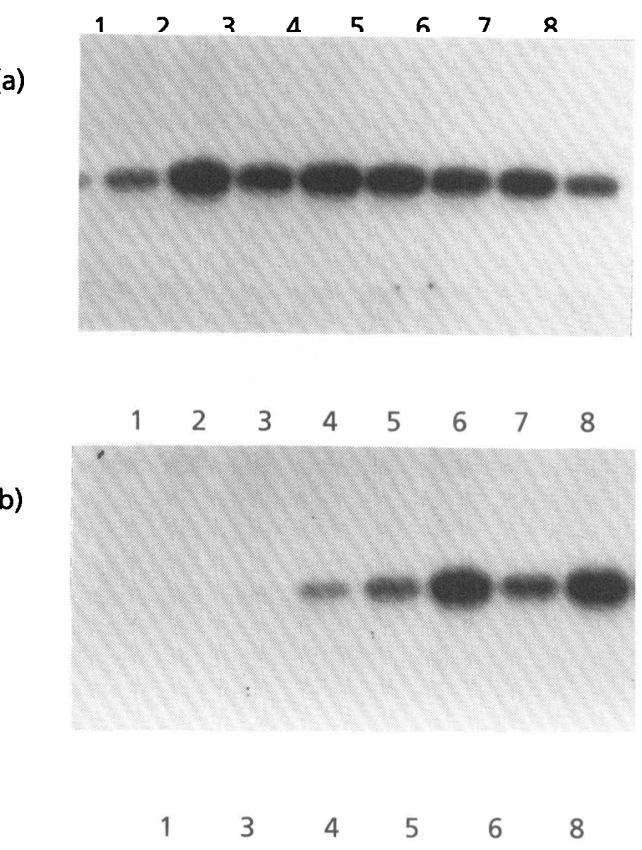

(c)

\begin{abstract}
Fig. 2. $(a, b)$ Northern blots of $S$. cerevisiae BJ2168 RNA samples probed for actin mRNA (a) or Hsp26 mRNA (b). (c) Northern blot of PMY3(pUP41a) RNA probed for Hsp12 mRNA. The RNA samples were from unstressed cells growing at $25^{\circ} \mathrm{C}$ (lanes 1), cells treated for $40 \mathrm{~min}$ at $25^{\circ} \mathrm{C}$ with $2 \%$ (lanes 2), $4 \%$ (lanes 3), $6 \%$ (lanes 4 ), $8 \%$ (lanes 5 ) or $10 \%$ ethanol (lanes 6 ), and cells heat-shocked to $37^{\circ} \mathrm{C}$ (lanes 7) or $40^{\circ} \mathrm{C}$ (lanes 8 ) for $40 \mathrm{~min}$. Ten micrograms of RNA was loaded into each gel lane.
\end{abstract}

same UBI4 promoter-lac $Z$ fusion by methanol or heat shock (Kirk, 1993).

\section{The Hsp70 genes induced by ethanol are the same as those induced with heat shock}

Ethanol causes strong induction of proteins that comigrate on 1D gels with the heat-induced Hsp70 (Fig. 1). The Hsp 70 family proteins of $S$. cerevisiae are encoded by a multigene family comprising no less than 8-9 genes, three of which (SSA1,SSA3 and $S S A 4)$ are induced by heat shock (Craig \& Jacobsen, 1984; Werner-Washburne et al., 1987, 1989). To establish whether the Hsp70 genes induced by ethanol are the same as those induced by heat shock, proteins induced by ethanol in strains with one, two or three disruptions in Hsp70-family proteins (Table 1) were investigated by in vivo pulse-labelling at $25^{\circ} \mathrm{C}$ in the absence and presence of $6 \%$ ethanol. Labelled proteins with an apparent $M_{\mathrm{r}}$ greater than 40000 were then analysed on 1D $7 \%$ SDS gels (Fig. 3). This gel system was 
Table 2. Ethanol inducibility of HSP12 or UB/4 promoter-lacZ fusions

\begin{tabular}{|ccc|}
\hline Treatment & $\begin{array}{r}\text { Induction over 25 }{ }^{\circ} \mathbf{C} \text { basal } \\
\text { level (-fold) }\end{array}$ \\
\cline { 2 - 3 } & $\begin{array}{c}\text { PMY3(pUP41a) } \\
\text { (HSP12-lacZ) }\end{array}$ & $\begin{array}{c}\text { PMY501 } \\
\text { (UBI4-lacZ) }\end{array}$ \\
& & \\
Ethanol: & 12 & $5 \cdot 2$ \\
$4 \%, 40$ min & 12 & $5 \cdot 2$ \\
$6 \%, 40$ min & 3 & $3 \cdot 5$ \\
$8 \%, 40$ min & 0 & $2 \cdot 5$ \\
$10 \%, 40$ min & & \\
Heat shock: & 61 & $4 \cdot 5$ \\
$25-39{ }^{\circ} \mathrm{C}, 40$ min & & \\
\hline
\end{tabular}
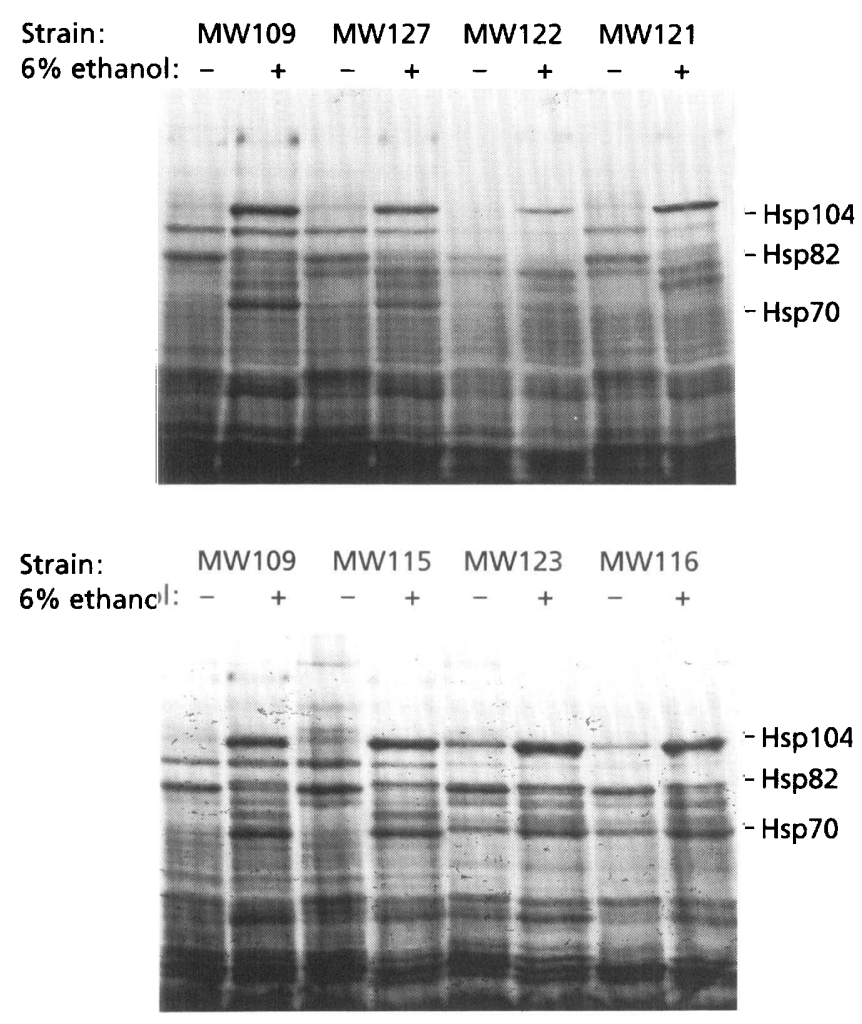

Fig. 3. Analysis on a $7 \%$ gel of the proteins with $M_{\mathrm{r}}$ greater than 40000 labelled in a $40 \mathrm{~min}$ pulse-labelling of the Hsp70 gene disruption strains listed in Table 1 , in the absence (-) and presence $(+)$ of $6 \%$ ethanol.

employed since the products of genes $S S A 1-4$ are not clearly resolved from each other even on two-dimensional gels (Werner-Washburne et al., 1989).

Fig. 3 shows that the Hsp70 induction by ethanol is due almost entirely to one or more of genes $S S A 1, S S A 3$ and SSA4, since it was completely abolished in a strain (MW121; Table 1) disrupted in all three of these genes. There was however substantial Hsp70 induction in strain
MW115 that lacks the $S S A 3$ and $S S A 4$ products, so $S S A 1$ is clearly strongly ethanol-inducible. There was also strong Hsp70 induction in a strain that lacked both the $S S A 1$ and $S S A 2$ products (MW123; Fig. 3 ), and in a strain which lacked the $S S A 1, S S A 2$ and $S S A 3$ products (MW116). Clearly therefore SSA4 is also ethanol-inducible. Fig. 3 therefore shows the strong Hsp70 induction by ethanol to be due to the induction of $S S A 1$, $S S A 4$ and possibly $S S A 3$. These are the three $S$. cerevisiae Hsp70 genes which are also strongly activated by heat shock, although one of them ( $S S A 1$ ) shows significant expression in unstressed cells (Craig \& Jacobsen, 1984; Werner-Washburne et al., 1987, 1989). Fig. 3 also shows a high synthesis of Hsp104, Hsp82 and Hsp70 in the absence of ethanol in those strains that lack functional $S S A 1$ and SSA2 genes (strains MW123 and MW116 labelled in the absence of ethanol). This constitutive expression of heat-shock genes in ssa 1 ssa 2 strains has been previously noted by Craig \& Jacobsen (1984) and WernerWashburne et al. (1987).

\section{Ethanol causes the two major changes to plasma- membrane protein composition also seen with heat shock, a rapid decline in plasma-membrane ATPase levels and acquisition of Hsp30}

Damage to the plasma membrane is thought to be a major cause of ethanol toxicity (see Introduction). While the effects of ethanol on the lipids of this membrane have been the subject of considerable study (see Introduction), there has been no investigation of whether ethanol influences plasma-membrane protein composition. At least one activity of this membrane (plasma membrane ATPase) influences both heat and ethanol tolerance (Panaretou \& Piper, 1990). Both heat stress (Coote et al., 1991; Coote, 1993) and ethanol (Cartwright et al., 1987; Rosa \& SaCorreia, 1991) cause stimulation of this ATPase activity, the resulting enhancement of catalysed proton efflux from the cell helping to counteract the depolarization of the plasma membrane resulting from the stress-induced increases in membrane permeability (see Introduction).

With heat shock a single integral membrane Hsp (Hsp30) is targeted to the plasma membrane (Panaretou \& Piper, 1992; Récnacq \& Boucherie, 1993). Also, levels of the proton-pumping plasma-membrane ATPase decline (Panaretou \& Piper, 1992). Since Hsp30 is a membrane protein its total cellular abundance is considerably less than that of major soluble Hsps such as Hsp104, Hsp82, Hsp70 or Hsp26. It is therefore not prominent on gels of total cell heat- or ethanol-induced proteins (Fig. 1), its analysis requiring the preparation of membrane fractions.

Brief treatment of BJ2168 cells with 6 or $8 \%$ ethanol resulted in a reduction in levels of the most abundant plasma-membrane protein, plasma-membrane ATPase (Fig. 4a) and induction of Hsp30 (Fig. 4b). These are the same two changes to plasma-membrane protein composition previously shown to result from sublethal heat shock of this same strain (Panaretou \& Piper, 1992). Hsp30 was induced to similar levels by heat shock and treatment with $6 \%$ ethanol, although its induction was 

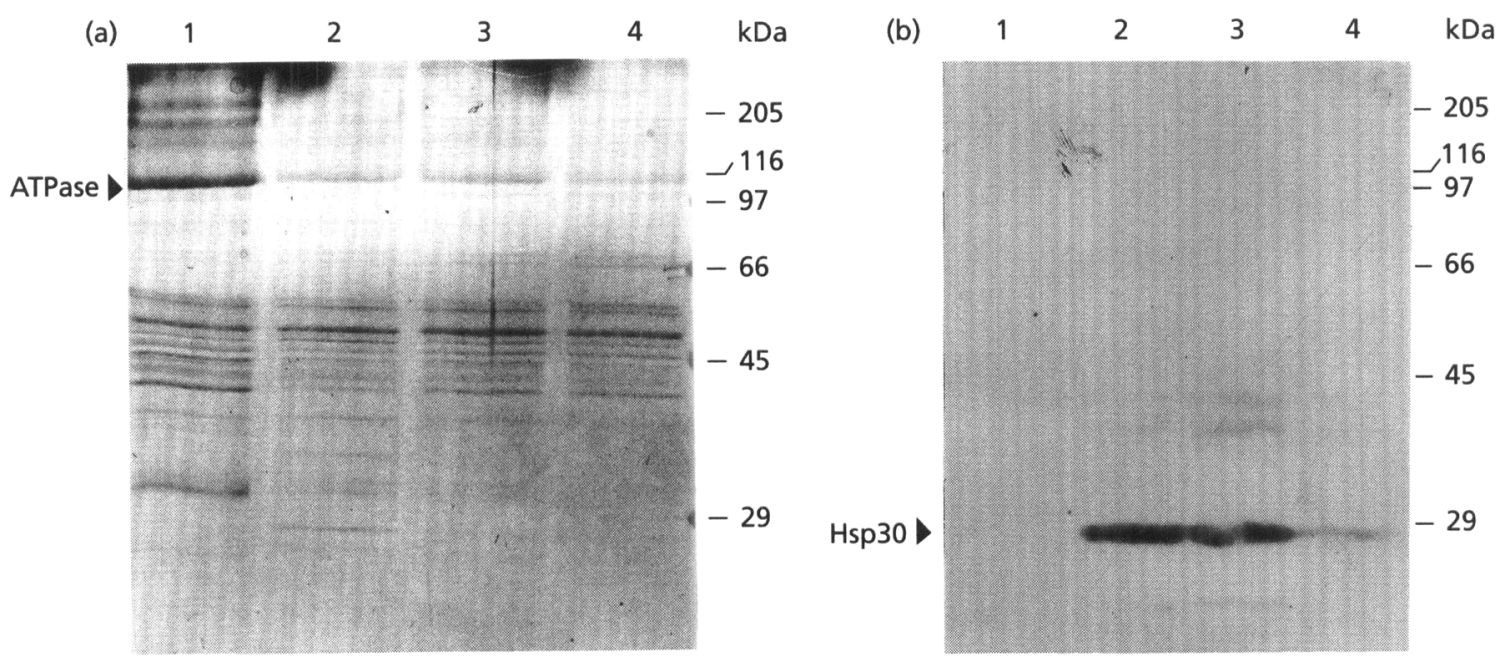

Fig. 4. Major changes to the protein composition of the plasma membranes of BJ2168 cells following a 40 min heat shock at $40^{\circ} \mathrm{C}$ or a $40 \mathrm{~min}$ ethanol treatment at $25^{\circ} \mathrm{C}$. (a) Coomassie-brilliant-blue-stained gel of plasma-membrane protein samples; (b) an identical gel fractionation of the same samples, blotted and probed for Hsp30 using an anti-Hsp30 antiserum. Lanes: 1, exponentially growing cells; 2 , cells heat shocked for 40 min at $40{ }^{\circ} \mathrm{C} ; 3$, cells treated with $6 \%$ ethanol; 4 , cells treated with $8 \%$ ethanol. Thirty micrograms of total plasma membrane protein was loaded in each gel lane.

appreciably less with $8 \%$ ethanol (Fig. 4b). The ATPase loss with heat shock appears to reflect protein turnover in the absence of de novo synthesis since it still occurs in cells subjected to these stresses in the presence of cycloheximide (K. Talreja \& P. W. Piper, unpublished results). This progressive and relatively rapid loss of ATPase from the plasma membrane with heat or ethanol stress almost certainly influences the capacity of the cells for sustained maintenance of homeostasis during the stress. Using the appropriate mutants future studies can determine whether this reduction in plasma-membrane ATPase, or the acquisition of $\mathrm{Hsp} 30$, contribute significantly to ethanol or heat tolerance.

\section{DISCUSSION}

The results described here provide further evidence of the strong similarity between the cellular responses to ethanol and to heat shock. The forms of Hsp90 and Hsp70 induced by ethanol are shown to be the same as those induced by heat (Figs 1 and 3). Also these two stresses are shown to have similar effects on the levels of two major integral plasma-membrane proteins, the ATPase and Hsp30 (Fig. 4). While it has long been known that cells alter the lipid composition of their membranes in response to ethanol, this is the first demonstration that they also rapidly alter the protein composition of the plasma membrane.

There is a critical threshold (4\%) for induction of heatshock proteins by ethanol (Figs 1 and 2). Maximal induction is seen at higher ethanol levels which are different for individual heat-shock proteins and heatshock promoters (Figs 1, 2 and 4 and Table 2). Increasing ethanol levels from 4 to $10 \%$ increases the synthesis of
Hsp104, Hsp70 and Hsp26 in strain BJ2168 (Figs 1, 2b). However Hsp30 induction declines in this strain as ethanol levels increase above $6 \%$ (Fig. 4), as does Hsp12 in strain PMY3(pUP41a) (Fig. 2c, Table 2). This suggests that the level of induction of different heat shock genes is regulated by factor(s) that sense different sublethal ethanol concentrations.

The effects of alkanols on cell inactivation relate to their lipid solubility, indicating that they act in a non-specific way to disorder the membrane lipids (Leao \& van Uden, 1982; Van Uden, 1984a). Methanol is the least toxic, inactivating cells only above $18-20 \%$, even though the heat-shock element sequences of yeast promoters are induced maximally at about $10 \%$ methanol (Kirk \& Piper, 1991b). Ethanol is cytotoxic at lower levels (van Uden, 1984a), inducing most Hsps maximally at 4-10\% (Fig. 1). Further increases in the length of the aliphatic chain and lipophilic character of the alcohol increase its cytotoxicity, presumably due to the increased membrane solubility (Jones, 1989). They also increase the potential for induction of heat-shock protein (Gropper \& Rensing, 1993), presumably due to an increased capacity for the alcohol to destabilize the hydrophobic interactions that maintain protein conformations.

In vegetative cells tolerances of potentially lethal heat and ethanol are highest in cells with low cAMP-dependent protein kinase activity, increasing as cultures progress from exponential to early-stationary phase (Casey \& Ingledew, 1986; Iida, 1988; Piper, 1993). Increased ethanol tolerance is inducible, frequently occurring under the same conditions as those leading to increased thermotolerance (Plesset et al., 1982; Watson, 1990; Sanchez et al., 1992; Costa et al., 1993). With the close parallels between the physiological states leading to ethanol 
tolerance and thermotolerance in yeast it is not surprising that determinants of thermotolerance are also important influences on ethanol tolerance. Thus loss of Hsp104 has been shown to reduce both ethanol tolerance, tolerance to heat, and heat induced tolerance to ethanol (Parsell et al., 1991; DeVirgilio et al., 1991; Sanchez et al., 1992). Besides Hsps, several physiological changes resulting from heat or ethanol exposure are also important in determining cellular tolerances to these stresses (Mager \& MoradasFerreira, 1993; Piper, 1993; Parsell \& Lindquist, 1993). The rapid loss of plasma membrane ATPase protein with ethanol stress (Fig. 4a) contrasts with the ethanol stimulation of the activity of this enzyme (see Introduction). Both these influences on the ATPase will affect its role in maintenance of homeostasis (Serrano, 1991) and should therefore have important effects on tolerance to prolonged exposure to ethanol. Other factors that influence homeostasis will also influence tolerance to ethanol and heat. Thus cells survive heat stress best at $\mathrm{pH} \mathrm{6-7}$ (Cheng \& Piper, 1994), when their extracellular $\mathrm{pH}$ approximates to intracellular $\mathrm{pH}$. The same probably applies to exposure to alkanols and other agents that increase membrane permeability.

\section{ACKNOWLEDGEMENTS}

We thank E. Craig for strains and M. Amelia Amorim for technical assistance. This work was supported by a SERC postgraduate studentship (B.P.), a SERC CASE studentship supported by Unilever Plc (K.T.) and SERC project grants GR/F72932 and GR/F72949.

\section{REFERENCES}

Aguilera, A. \& Benitez, T. (1989). Synergistic effects of ethanol and temperature on yeast mitochondria. Curr Microbiol 18, 179-188.

Ananthan, J., Goldberg, A. L. \& Voellmy, R. (1985). Abnormal proteins serve as eukaryotic stress signals and trigger the activation of heat shock genes. Science 232, 522-524.

Borkovich, K. A., Farrelly, F. W., Finkelstein, D. B., Taulien, J. \& Lindquist, S. (1989). hsp82 is an essential protein that is required in higher concentrations for growth of cells at higher temperatures. Mol Cell Biol 9, 3919-3930.

Cartwright, C. P., Veazey, F. J. \& Rose, A. H. (1987). Effect of ethanol on activity of the plasma membrane ATPase in, and accumulation of glycine by, Saccharomyces cerevisiae. J Gen Microbiol 133, 857-865.

Casey, G. P. \& Ingledew, W. M. (1986). Ethanol tolerance in yeasts. CRC Crit Rev Microbiol 13, 219-280.

Cheng, L. \& Piper, P. W. (1994). Weak acid preservatives block the heat shock response and heat-shock-element-directed lac $Z$ expression of low $\mathrm{pH}$ Saccharomyces cerevisiae cultures, an inhibitory action partially relieved by respiratory deficiency. Microbiology 140 , 1085-1096.

Coote, P. J. (1993). Mechanisms of induced thermotolerance in Saccharomyces cerevisiae. PhD thesis, University of Nottingham.

Coote, P. J., Cole, M. B. \& Jones, M. V. (1991). Induction of increased thermotolerance in Saccharomyces cerevisiae may be triggered by a mechanism involving intracellular $\mathrm{pH}$.J Gen Microbiol 137, 1701-1708.

Costa, V., Reis, E., Quintanilha, A. \& Moradas-Ferreira, P. (1993). Acquisition of ethanol tolerance in Saccharomyces cerevisiae: the key role of the mitochondrial superoxide dismutase. Arch Biochem Biophys 300, 608-614.

Craig, E. A. \& Jacobsen, K. (1984). Mutations of the heat-inducible 70 kilodalton genes of yeast confer temperature-sensitive growth. Cell 38, 841-849.

DeVirgilio, C., Piper, P. W., Boller, T. \& Wiemken, A. (1991). Acquisition of thermotolerance in Saccharomyces cerevisiae without heat shock protein Hsp104 and in the absence of protein synthesis. FEBS Lett 288, 86-90.

Finley, D., Ozkaynak, E. \& Varshavsky, A. (1987). The yeast polyubiquitin gene is essential for resistance to high temperatures, starvation and other stresses. Cell 48, 1035-1048.

Gropper, T. \& Rensing, L. (1993). Inhibitors of proteases and other stressors induce low molecular weight heat shock proteins in Saccharomyces cerevisiae. Exp Mycol 17, 46-54.

lida, H. (1988). Multistress resistance of Saccharomyces cerevisiae is generated by insertion of retrotransposon 'Ty into the 5 ' coding region of the adenylate cyclase gene. Mol Cell Biol 8, 5555-5560.

Jones, R. P. (1989). Biological principles for the effects of ethanol. Enzyme Micrab Tecbnol 11, 130-153.

Kirk, N. (1993). Process effectiveness of yeast expression vectors. $\mathrm{PhD}$ thesis, University of London.

Kirk, N. \& Piper, P. W. (1991a). The determinants of heat shock element-directed lac $Z$ expression in Sacharomyces cerevisiae. Yeast $\mathbf{7}$, 539-546.

Kirk, N. \& Piper, P. W. (1991b). Methanol as a convenient inducer of heat shock element-directed heterologous gene expression in yeast. Biotech Lett 13, 465-470.

Leao, C. \& van Uden, N. (1982). Effects of ethanol and other alkanols on the kinetics and the activation parameters of thermal death in Saccharomyces cerevisiae. Biotechnol Bioeng 24, 1581-1590.

Leao, C. \& van Uden, N. (1984). Effects of ethanol and other alkanols on passive proton influx in the yeast Saccharomyces cerevisiae. Biochim Biophys Acta 774, 43-48.

Leao, C. \& van Uden, N. (1985). Effects of ethanol and other alkanols on the temperature relations of glucose transport and fermentation in Saccharomyces cerevisiae. Appl Microbiol Biotecbnol 22, 359-363.

Lloyd, D., Morrell, S., Carlsen, H. N., Degn, H., James, P. E. \& Rowlands, C. C. (1993). Effects of growth with ethanol on fermentation and membrane fluidity of Saccharomyces cerevisiae. Yeast 9, 825-833.

Mager, W. H. \& Moradas-Ferreira, P. (1993). Stress response of yeast. Biochem J 290, 1-13.

Neves, M.-J. \& Francois, J. (1992). On the mechanism by which a heat shock induces trehalose accumulation in Saccharomyces cerevisiae. Biochem J 288, 559-564.

Nover, L. (1991). The beat shock response. Boston and London: CRC Press.

Panaretou, B. \& Piper, P. W. (1990). Plasma-membrane ATPase action affects several stress tolerances of Saccharomyces cerevisiae and Schizosaccharomyces pombe as well as the extent and duration of the heat shock response. J Gen Microbiol 136, 1763-1770.

Panaretou, B. \& Piper, P. W. (1992). The plasma membrane of yeast acquires a novel heat shock protein ( $\mathrm{Hsp} 30)$ and displays a decline in proton-pumping ATPase levels in response to both heat shock and the entry to stationary phase. Eur J Biocbem 206, 635-640.

Parsell, D. A. \& Lindquist, S. (1993). The function of heat shock proteins in stress tolerance: degradation and reactivation of damaged proteins. Annu Rev Genet 27, 437-496.

Parsell, D. A., Sanchez, Y., Stitzel, J. D. \& Lindquist, S. (1991). 
Hsp104 is a highly conserved protein with two essential nucleotide binding sites. Nature 353, 270-273.

Petko, L. \& Lindquist, S. (1986). HSP26 is not required for growth at high temperatures, nor for thermotolerance, spore development, or germination. Cell 45, 885-894.

Piper, P. W. (1993). Molecular events associated with the acquisition of heat tolerance in the yeast Saccharomyces cerevisiae. FEMS Microbiol Rev 11, 339-356.

Piper, P. W., Curran, B., Davies, M. W., Hirst, K., Lockheart, A. \& Seward, K. (1988). Catabolite control of the elevation of PGK mRNA levels by heat shock in Saccharomyces cerevisiae. Mol Microbiol 2, 353-361.

Plesset, J., Palm, C. \& McLaughlin, C. S. (1982). Induction of heat shock proteins and thermotolerance by ethanol in Saccharomyies cerevisiae. Biochem Biophys Res Commun 108, 1340-1345.

Praekelt, U. M. \& Meacock, P. A. (1990). HSP12, a new heat shock gene of Saccharomyces cerevisiae: analysis of structure, regulation and function. Mol Gen Genet 223, 97--106.

Récnacq, M. \& Boucherie, H. (1993). Isolation and sequence of HSP30, a yeast heat-shock gene coding for a hydrophobic membrane protein. Curr Genet 23, 435-442.

Rosa, M. F. \& Sa-Correia, I. (1991). In vivo activation by ethanol of plasma membrane ATPase of Saccharomyces cerevisiae. Appl Environ Microbiol 57, 830-835.

Rose, A. H. (1993). Composition of the envelope layers of Saccharomyces cerevisiae in relation to flocculation and ethanol tolerance. J Appl Bacteriol Symp Suppl 74, 110S-118S.

Sanchez, Y., Taulein, J., Borkovich, K. A. \& Lindquist, S. (1992).
Hsp104 is required for tolerance to many forms of stress. EMBO J 11, 2357-2364.

Serrano, R. (1991). Transport across yeast vacuolar and plasma membranes. In The Molecular Biology of the Yeast Saccharomyces. Genome dynamics, protein synthesis, and Energetics, pp. 523-585. Edited by J. N. Strathern, E. W. Jones \& J. R. Broach. Cold Spring Harbor, NY: Cold Spring Harbor Laboratory Press.

Sherman, F., Fink, G. R. \& Hicks, J. B. (1983). Methods in Yeast Genetics. Cold Spring Harbor, NY: Cold Spring Harbor Laboratory.

Susek, R. E. \& Lindquist, S. L. (1989). Hsp26 of Saccharomyces cerevisiae is related to the superfamily of small heat shock proteins, but is without a demonstrable function. Mol Cell Biol 9, 5265-5271.

van Uden, N. (1984a). Effects of ethanol on the temperature relations of viability and growth in yeast. Crit Rev Biotechnol 1, 263-272.

van Uden, N. (1984b). Temperature profiles of yeasts. Adv Microb Physiol 25, 195-251.

Watson, K. (1990). Microbial stress proteins. Adv Microb Pbysiol 31, 183-223.

Werner-Washburne, M., Stone, D. E. \& Craig, E. A. (1987). Complex intractions among members of an essential subfamily of hsp70 genes in Saccharomyces cerevisiae. Mol Cell Biol 7, 2568-2577.

Werner-Washburne, M., Becker, J., Kosic-Smithers, J. \& Craig, E. A. (1989). Yeast HSP70 levels vary in response to the physiological status of the cell. $J$ Bacteriol 171, 2680-2688.

Received 8 June 1994; revised 12 July 1994; accepted 22 July 1994. 